\title{
Forensic Application of FM-CW and Pulse Radar
}

\author{
Robert S. Freeland ${ }^{*}$, Michelle L. Miller ${ }^{\mathrm{b}}$, Ronald E. Yoder ${ }^{\mathrm{a}}$, Steven K. Koppenjan ${ }^{\mathrm{c}}$ \\ ${ }^{a}$ Department of Biosystems Engineering and Environmental Science \\ The University of Tennessee, Knoxville, TN 37996-4531, USA \\ ${ }^{b}$ Department of Anthropology \\ The University of Tennessee, Knoxville, TN 37996-0720, USA \\ ${ }^{c}$ Bechtel Nevada, Special Technologies Laboratory \\ 5520 Ekwill St., Santa Barbara, CA 93111, USA
}

\begin{abstract}
Ground-penetrating radar (GPR) technology has supplied vital assistance in criminal investigations. However, law enforcement personnel desire further developments such that the technology is rapidly deployable, and that it provides both a simple user interface and sophisticated target identification. To assist in the development of target identification algorithms, our efforts involve gathering background GPR data for the various site conditions and circumstances that often typify clandestine burials. For this study, forensic anthropologists established shallow-grave plots at The University of Tennessee Anthropological Research Facility (ARF) that are specific to GPR research. These plots contain donated human cadavers lying in various configurations and depths, surrounded by assorted construction material and backfill debris.
\end{abstract}

We scanned the plots using two GPR technologies: (1) a multi-frequency synthetic-aperture FM-CW radar (200-700 MHz) (GPR-X) developed by the U.S. Department of Energy's (DOE) Special Technologies Laboratory (STL), Bechtel Nevada (Koppenjan et al., 2000), and (2) a commercial pulse radar (SIR-20) manufactured by Geophysical Survey Systems, Inc. (400 and $900 \mathrm{MHz})(\mathrm{GSSI})$.

The sweep-frequency data show the large biological mass decomposing within the torso as encircled "hot spots." The 400-MHz pulse radar exhibit major horizontal reflectors above the body, with shadow reflectors (horizontal multiples) occurring beneath the body at $60 \mathrm{~cm}$ depth. The 400-MHz antenna was able to discern the grave walls and folded tarp covering the lower body. Under these moist, clay-rich conditions, the $900-\mathrm{MHz}$ antenna was able to penetrate slightly beyond $30 \mathrm{~cm}$ beneath the concrete layer. However, neither system was able to penetrate beyond a one meter depth in the moist, clay-rich soil (fine, mixed, thermic Typic Paleudalf). Example scans from each system are provided, along with a discussion of the survey protocol and general performance.

Keywords: Government agencies, Radar methods, SAR, Soils

\footnotetext{
${ }^{*}$ Corresponding author: E-mail: $<\underline{\text { rfreelan@utk.edu }}>$ FAX: 865-974-4514
} 


\section{Introduction}

Professional investigators may have some limited knowledge of ground-penetrating radar (GPR), but most do not employ the technology because they lack sufficient experience with data interpretation and equipment operation (Drew, 1996). Both equipment costs and consultant fees remain high, and at times, performance shortcomings and failures cause cynicism whenever investigators deploy GPR on challenging sites. Given the layperson's difficulty of interpreting raw radar data in distinguishing valid forensic targets, successful GPR operation currently requires proficiency and experience. Simplified operation and interpretation for both novice and professional operators would greatly benefit law enforcement investigations, while also allowing the technology to be more effective and more widely utilized.

Towards this goal, forensic anthropologists, soil scientists, and engineers are relating GPR data with cadaver targets. The University of California, Santa Barbara, The University of Florida, The University of Tennessee, and the U.S. Department of Energy's Special Technologies Laboratory (STL) are collaborating on this project. This project employs both a proprietary lightweight GPR unit and a commercial system.

\section{Current Application}

The Federal Bureau of Investigation (FBI) formed the Technology Assisted Search Team (TAST) in 1995 to assist the Evidence Response Team Unit. Its primary mission is to provide specialized high-tech support for cases where evidence retrieval is difficult. Ground-penetrating radar is one of the more frequently used tools of TAST, as local investigators ask this unit to locate bodies or bones that are thought to be clandestinely buried. (Clandestine burials tend to be shallow, often less than one meter.) Before this team decides to deploy its considerable resources, the probability of GPR being effective for the proposed site's survey conditions requires prior assessment. Needed are extensive reference databases of GPR performance for various overburden conditions and targets.

\section{Review of the Literature}

Doolittle et al. (2002) provides a generalized map of the conterminous United States of America (USA) based upon estimated effective ground suitability index for GPR profiling. The potential for successful GPR soil investigations across the eastern and western conterminous USA appears good, with poor potential in the Great Plains.

Mellett (1996) reviewed several case studies of forensic and archeological investigations, commenting on the causes of successes and failures. Obviously, forensic targets change over time, with decomposing targets cause signal whiteout at and below the remains, and skeletal remains providing a clear hyperbolic echo. Soil properties, inorganic anomalies, overburden interference, and decomposition state combine to influence GPR performance. Anomaly detection helps to reduce widespread excavations (eliminating from the search those sites where 
there are no soil disturbances or anomalies) and may aid in obtaining site-specific excavation search warrants.

Hammon et al. (2000) conducted GPR simulations on models of human remains. Models were shallow $(40 \mathrm{~cm})$ and deep $(80 \mathrm{~cm})$. They found feature resolution of a human target requires a survey frequency of $900 \mathrm{MHz}$ or greater, and an increment between recording stations of $10 \mathrm{~cm}$ or less. Signal attenuation was the main limitation on data quality, which both the surrounding soil and the biomass within the body influence. They reported biological tissues are conductive; thus, imaging human bodies are restricted to the soil/skin interface and shallow tissue interfaces. Their simulation showed a low-amplitude reflection shadow zone occurring beneath a body because of high GPR attenuation within the body. Maximum reflection amplitude from a decomposed model was determined to be $60 \%$ greater than for an equivalent fleshed model. They predicted a significant change in the data would take place with the collapse of the abdominal cavity, which results from the concave reflecting surface.

Miller (2002) generated 3-D representations of decomposing human cadavers at the ARF. Using the GPR-X and GSSI systems, she obtained radargrams of the plots at monthly intervals. She was able to distinguish the decomposing body targets from that of construction debris, based upon temporal shape changes within 3-D data (Miller et al., 2002).

\section{$\underline{\text { Objectives }}$}

The objectives of this project are twofold:

1) To contrast the raw data of pulse and FM-CW radar technologies operating over fleshed cadavers that were buried shallow in a clay-rich soil, and

2) To evaluate field data with the GPR simulation results of Hammon et al. (2000) and case studies reported by Mellett (1996).

\section{$\underline{\text { Research site }}$}

\section{Equipment and Methods}

The University of Tennessee's ARF is an outdoor laboratory for scientific study of human decomposition. Miller (2002) established numerous shallow burial plots specifically for repetitive and controlled GPR testing. The site contains multiple human decomposition plots of varying depths and burial environments. For this project, donated nonembalmed cadavers at various stages of decomposition were buried, each lying alongside (or covered by) interfering anomalies that are often found in clandestine burials (i.e., construction debris of metal, wood, stones, and plastic). The site's soil, formed in colluvium over old alluvium, is a fine, mixed, thermic Typic Paleudalf (Ammons et al., 2001). The soil horizons, although very clayey, drain well. The undisturbed soil horizon textures range from silt loam in the surface to red clay in the subsoil, a very difficult medium for GPR imaging. The locked-fence research site has a heavy forested canopy with tree roots extending throughout the subsurface. Various artifacts lay embedded within the soil from previous forensic experiments. 
Figure 1 illustrates a typical plot, 1.8-m wide by 2.4-m long, that contains the remains of a fleshed cadaver. A folded plastic tarp covers the lower body. The right half of the plot has undisturbed soil, with the left half containing a grave that is $60-\mathrm{cm}$ deep and backfilled with the excavated soil. A $10-\mathrm{cm}$ thick concrete pad covers this plot.

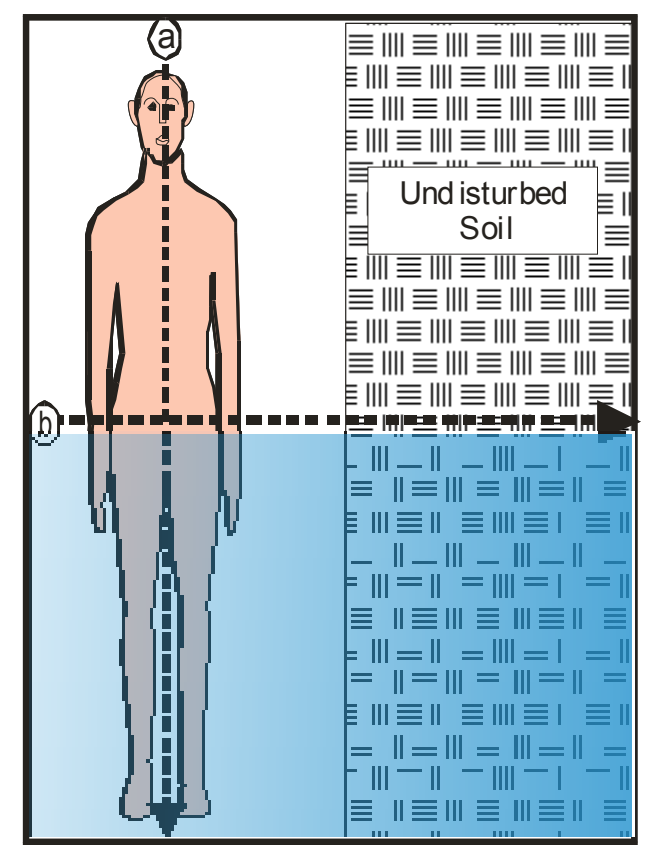

Figure 1. Plot layout illustrating survey transects (a) head to foot and (b) across hips to undisturbed soil. A folded plastic tarp covered the lower body.

\section{Synthetic-aperture radar FM-CW (GPR-X)}

The developers designed the GPR-X as a portable, synthetic-aperture multiple-frequency system operating in reflection mode over a 200-700 MHz range. During data processing, sequences of 128 coherent backward-propagating procedures form a composite representation. The image becomes an overlay of 128 holographic images, each for every coherent frequency step. Koppenjan et al. (2000) stated when using this method, diffraction is fully compensated in both range and cross-range directions; thereby, improving overall image quality.

\section{$\underline{\left.\text { Pulse radar (GSSI SIR }{ }^{\circledR}-20\right)}$}

We used a commercial system with GSSI Model 5103 (400 MHz) and GSSI Model 3101D $(900 \mathrm{MHz})$ antennas. The high-resolution antenna $(900 \mathrm{MHz})$ is marketed for thick $(>30 \mathrm{~cm})$ concrete inspections. The $400-\mathrm{MHz}$ antenna is employed for moderately shallow investigations (GSSI, 2002). 


\section{Procedure}

We obtained data using the STL FM-CW system at ARF on six plots once a month. For this report, we present data from these scans $(a)$ and $(b)$ of a single plot (Figure 1) along with scans obtained the SIR ${ }^{\circledR}-20$ using GSSI Model 5103 (400 MHz) and Model 3101D (900 MHz) antennas. In addition, we present time-elapsed scans obtained using the STL FM-CW system from a plot containing considerable construction debris.

For display commonality, both systems' raw data were color-enhanced and displayed using a 2-D visualization software package Transform Ver. 3.3 (Fortner Research, LLC). Raw SIR ${ }^{\circledR}-20$ data files (no post-process filtering) were converted to ASCII text for import to Transform using GSSI Radan to ASCII Conversion Utility Ver. 1.32.

\section{Results}

As expected, we found the clay-rich backfill to be very conductive and lossy, especially when moist. Neither system penetrated effectively beyond a one meter depth. Both systems resolved targets at shallow depths, with the pulse radar resolving flat reflectors such as the grave walls and a tarp partial covering the lower quads. All features were best resolved using a color scale as opposed to gray scale.

Figures $2 \mathrm{a}$ and $3 \mathrm{a}$ of the FM-CW data show the large biological mass decomposing within the torso as encircled "hot spots." Construction debris did not exhibit this characteristic feature, as did not the smaller appendages.

Figures $2 \mathrm{~b}$ and $3 \mathrm{~b}$ of the $400-\mathrm{MHz}$ pulse radar exhibit major horizontal reflectors above the body, with shadow reflectors (horizontal multiples) occurring beneath the body in Figure $2 \mathrm{~b}$ at 0.6-m depth. These results compare favorably to those predicted by the mathematical model reported by Hammon et al. (2000). The 400-MHz antenna was able to detect the grave walls and tarp. Under these moist, clay-rich conditions, the $900-\mathrm{MHz}$ antenna was able to penetrate approximately $0.5 \mathrm{~m}$ beneath the concrete layer (Figures $2 \mathrm{c}$ and $3 \mathrm{c}$ ).

Horizontal-slice ordering (Figure 4) illustrates time-elapsed changes, as detected by the FM-CW system, revealing the cadaver decompositional change (left column) over a five-month period (each month presented by row), while displaying the lack of change among the inorganic objects that were distributed adjacent to the grave (center and right columns). 


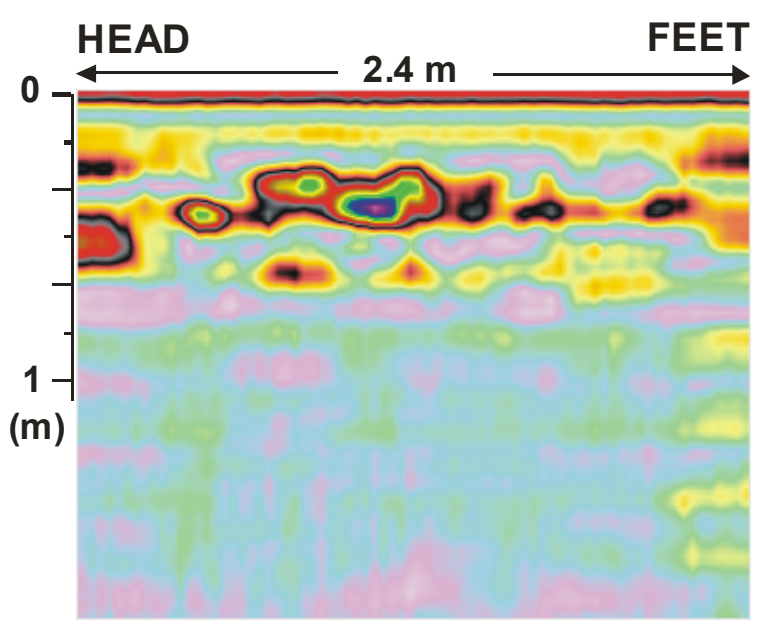

(a)

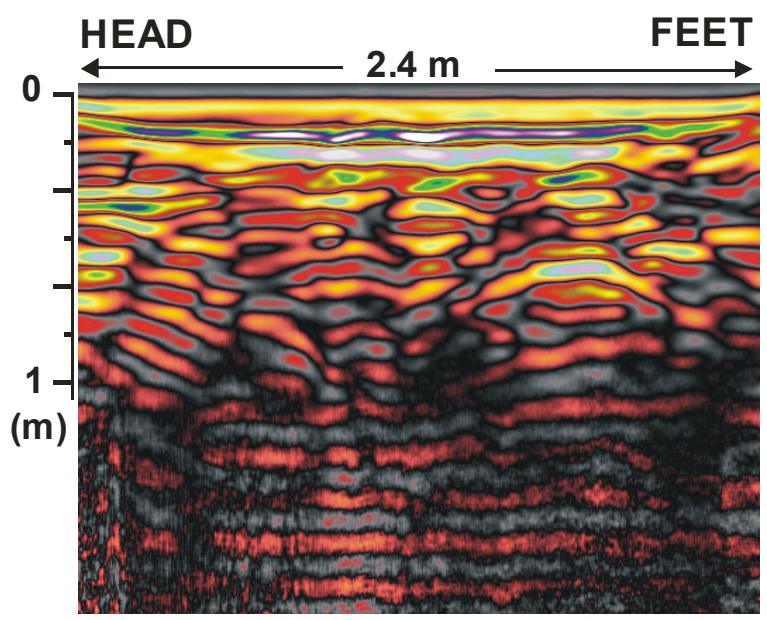

(b)

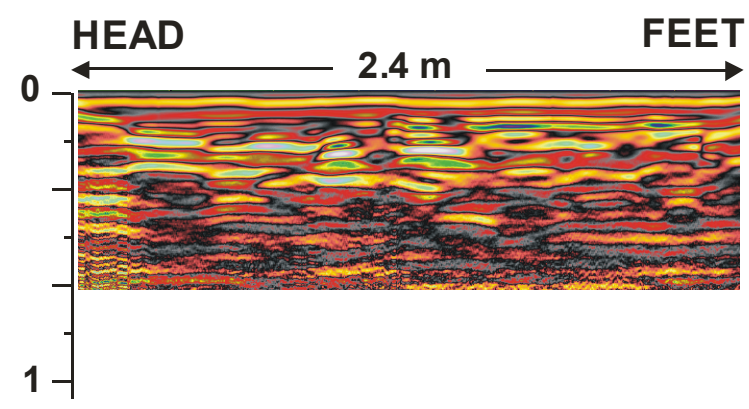

(m)

(c)

Figure 2. Head-to-foot scan (a) GPR-X FM-CW radar (200-700 MHz), (b) GSSI Models 5103 (400 MHx), and (c) 3101D (900 MHz).

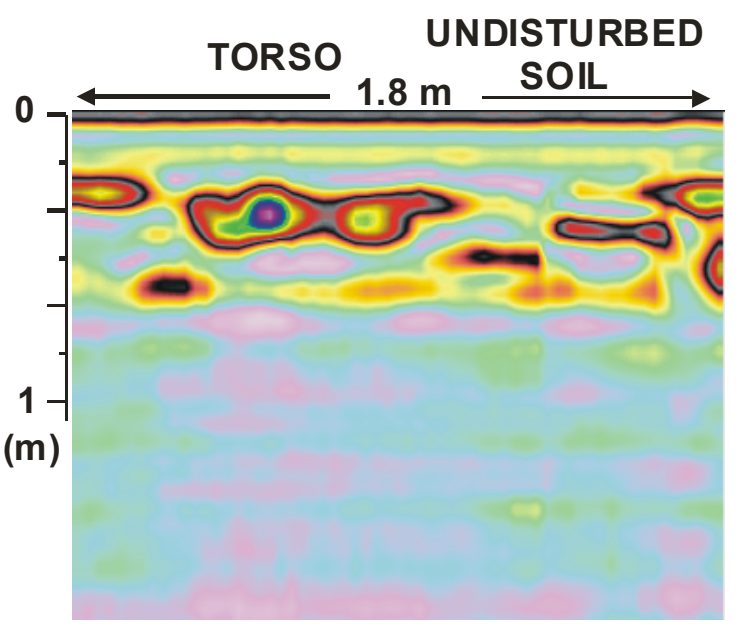

(a)

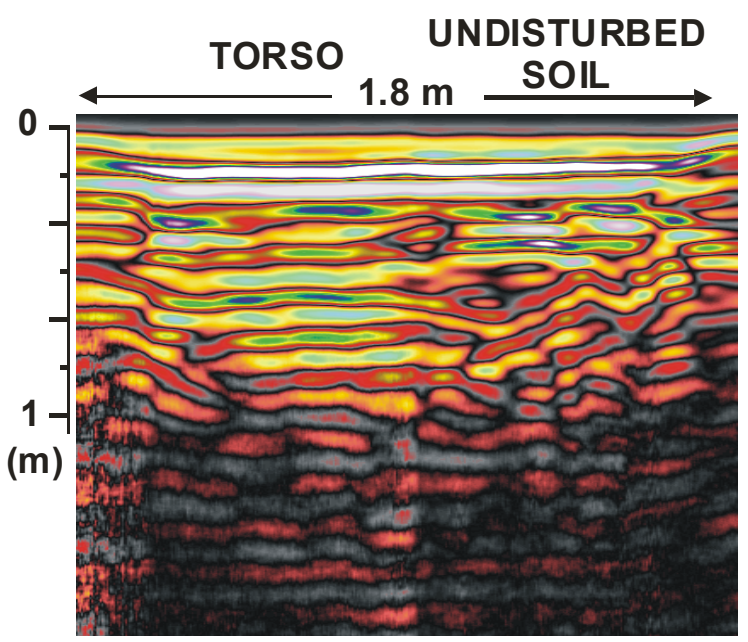

(b)

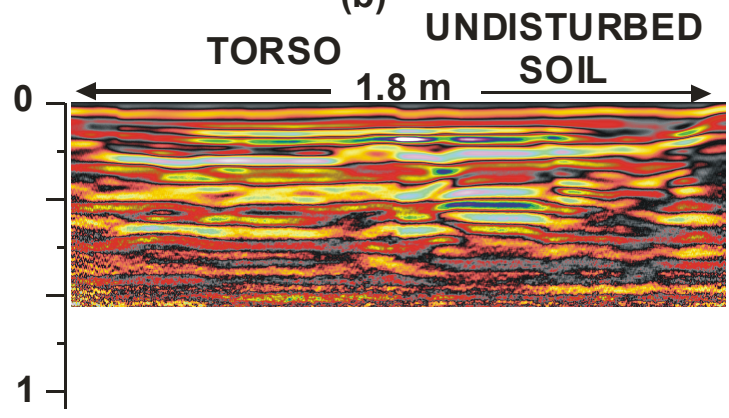

(m)

(c)

Figure 3. Hips-to-undisurbed soil scan of the (a) GPR-X FM-CW radar (200-700 MHz), (b) GSSI Models 5103 (400 MHx), and (c) 3101D (900 MHz). 

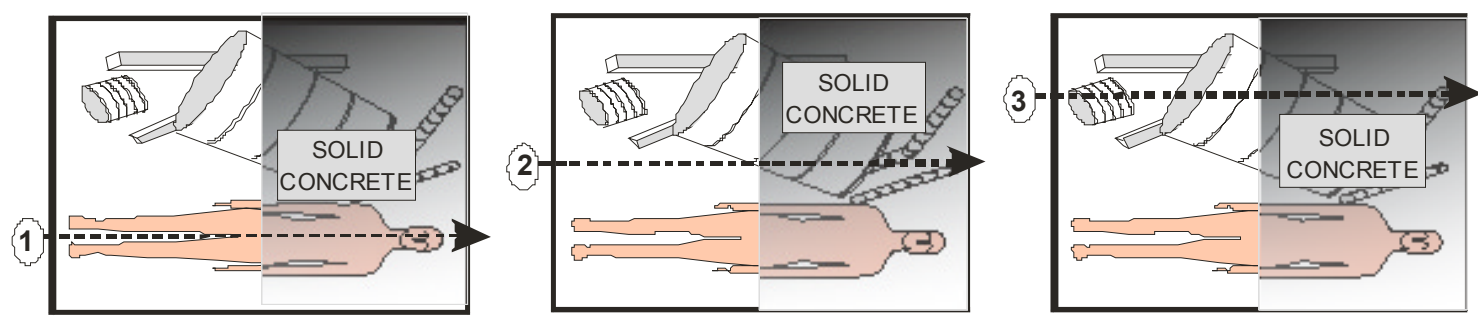

SURFACE
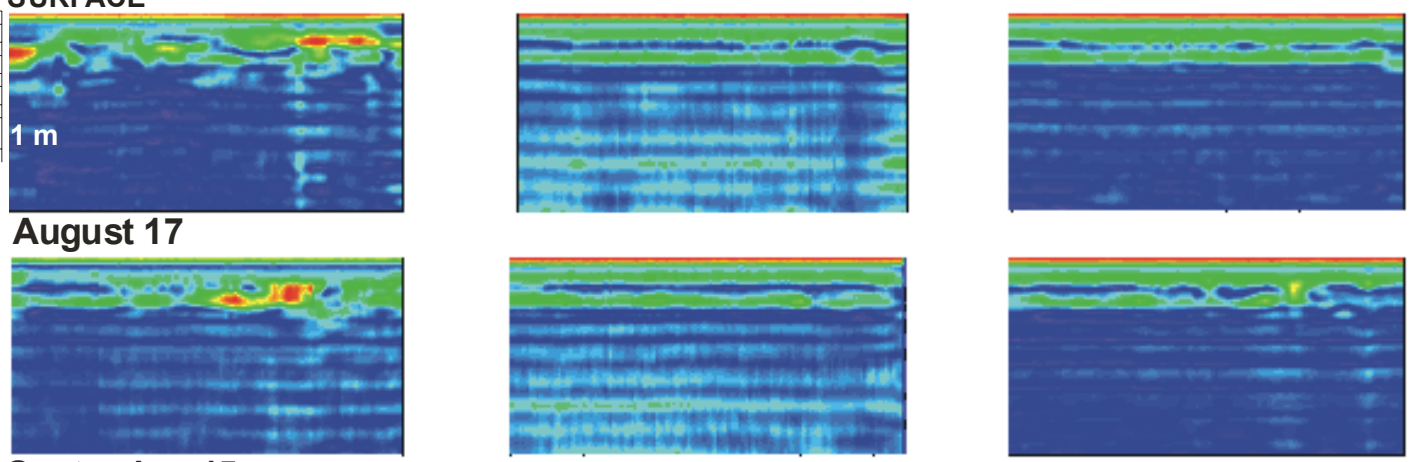

\section{September 15}
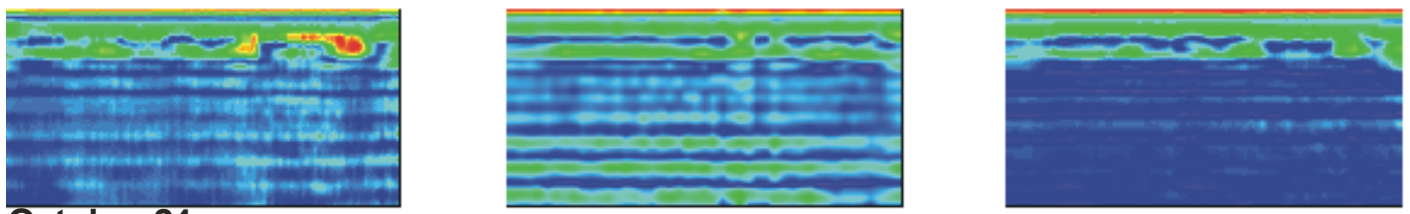

\section{October 24}
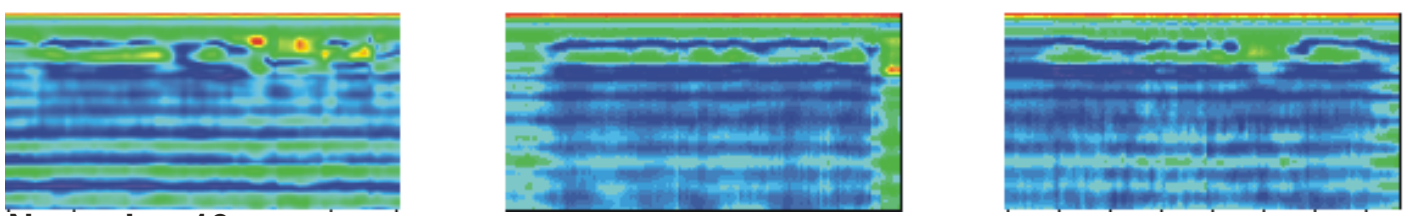

\section{November 19}

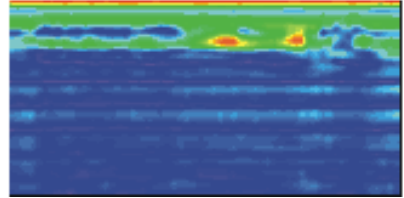

December 18

SCAN 1

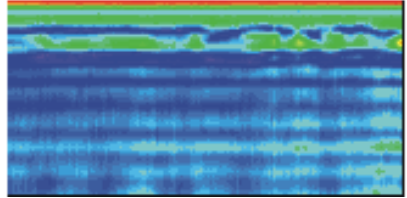

SCAN 2

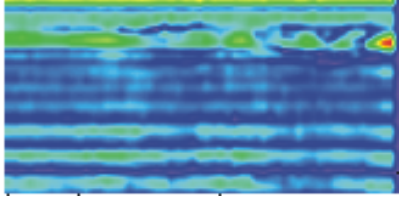

SCAN 3

Figure 4. Time slice comparison of GPR-X FM-CW radar (200-700 MHz) over five months. (Debris orientation and dimensions not to scale.) 


\section{Conclusions}

Neither system penetrated effectively beyond a one meter depth at this site; however, a shallow burial depth is common to clandestine burials underneath concrete, whereupon the act is often committed hastily. Furthermore, GPR applications at investigative sites that are considered not conducive to GPR performance may be successful if the grave is both shallow and capped with concrete.

During forensic investigations, present applications of GPR across sites involve locating soil disturbances and anomalies, in order to better focus follow-up intrusive probing and excavations. The FM-CW radar technologies, when operating over a decomposing cadaver, supply a unique "hot-spot" signature of the torso. This signature offers a specific real-time identifier of decomposing human remains. Searching for the signature pattern is most useful when surveying disturbed sites that are intermixed with debris.

Forensic applications of geophysical tools provide an essential and invaluable service to society. However, replicated plot research requiring direct access to decomposing human remains is somewhat hindered by societal mores, and is increasingly restricted by legal and permitting issues. Our applied research results support the GPR simulation results of Hammon et al. (2000) and field case studies reported by Mellett (1996). Thus, mathematical modeling and case studies offer alternative research methods for developing and applying new geophysical methods to forensic investigations.

\section{Acknowledgements}

DOE/NV/11718-745. The U.S. Department of Energy, National Nuclear Security Administration Nevada Operations Office supported this work under Contract No. DE-AC0896NV11718. The authors would like to thank Steven Schubert, DOE/NN-20, and Todd McCall, FBI-Evidence Response Team, for project funding, Bill Fitzgerald, DOE/STP for use of the GPR-X unit, and Dr. Murray Marks, The University of Tennessee Anthropology Department.

\section{Disclaimer}

Mention of a trade name, proprietary product, or specific equipment does not constitute a guarantee or warranty by the United States Government or any agency thereof or its contractors, subcontractors, or the authors, or The University of Tennessee, and it does not imply approval of a product to the exclusion of others that may be suitable. 


\section{APPENDIX A-TEST PLOT DESCRIPTION (Miller, 2002)}

Variables: 0.6-m deep (bottom of grave excavation) and plastic tarp covering lower quads.

Grave: The grave is $0.6-\mathrm{m}$ deep and is consistently level along the bottom with a slight downward slope beginning at the calves towards the feet. The grave walls flare outward with the base dimensions being $81-\mathrm{cm}$ wide at the head, $76-\mathrm{cm}$ wide at the feet and $1.98-\mathrm{m}$ long on both sides. The grave dimensions at ground level are 1.0-m wide at the head and feet and 2.4-m long. The plot is covered by $10-\mathrm{cm}$ thick concrete pad.

Body: This individual was buried May 2001. The body was in advanced decomposition with dried skin still present and covering the entire body, except for the skull, face, and neck, which were completely skeletonized. The body was placed in the test pit orientated east to west with the head at the eastern aspect. The body was positioned facing upwards with the head turned $90^{\circ}$ and facing north. The right arm was fully extended and was laying along the right side the body. The left arm was also along the left side of the body; however it was bent $90^{\circ}$ at the elbow and was lying across the mid-section of the body. The left wrist was also bent $90^{\circ}$ with the fingers pointing toward the feet (west) and the palmar surface pointing south. The legs were spread slightly. The left leg was fully extended with the heel of the foot in contact with the floor of the grave, and the foot facing upward, slightly rotated laterally with the toes pointing south. The right leg was rotated medially, slightly flexed at the hip and knee. The right foot was medially rotated with the medial aspect flat on floor of the grave and the toes pointing southward.

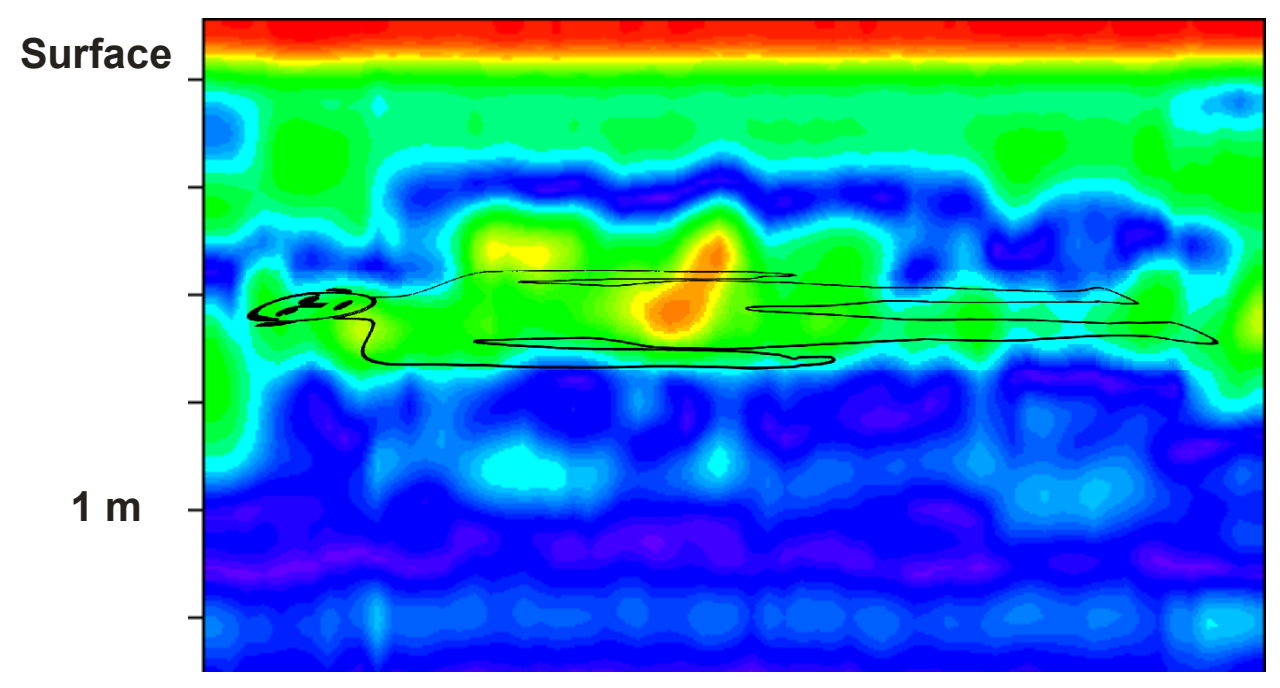

Figure A-1. Orientation of body in grave in relation to head-to-foot of sweep-frequency GPR-X survey (Oct. 2001). Bright encircled zone is at torso. 


\section{References}

Ammons, J.T., R.S. Freeland, R.E. Yoder, R.C. Wilson, M.K. Marks, and M.L. Miller. 2001. Soil evaluation of The University of Tennessee forensic research plots. Contract Report R111416005-01 to Bechtel Nevada. 10/01/2001.

Doolittle, J.A., Minzenmayer, F.E., Waltman, S.W., Benham, E.C., 2002. Ground-penetrating radar soil suitability map of the conterminous United States. Ninth International Conference on Ground-pentrating Radar. Proceedings of SPIE. 4758 (2002) 7-12.

Drew, J.R., 1996. Recommendation for the creation of a national organization of geophysicist dedicated to providing assistance to the law enforcement community. Symposium on the Application of Geophysics to Engineering and Environmental Problems, SAGEEP '96 Environmental and Engineering Geophysical Society. pp. 507-508.

GSSI, 2002. Product literature of GSSI antennas and products. Internet site http://www.geophysical.com accessed on January 14, 2002.Geophysical Survey Systems, Inc. North Salem, NH 03073-0097.

Hammon III, W.S., McMechan, G.A., and Zeng, X., 2000. Forensic GPR: finite-difference simulations of responses from buried human remains. Journal of Applied Geophysics. 45 (2000) 171-186.

Koppenjan, S.K., Allen, C.M., Gardner, D., Wong, H.R., Lee, H., Lockwood, S.J., 2000. Multifrequency synthetic-aperture imaging with a lightweight ground penetrating radar system. Journal of Applied Geophysics, (43) 251-258.

Mellett, J.S., 1996. GPR in forensic and archeological work: hits and misses. Symposium on the Application of Geophysics to Engineering and Environmental Problems, SAGEEP '96 Environmental and Engineering Geophysical Society. pp. 487-491.

Miller, M.L., 2002. GPR applications at the Anthropological Research Facility. Unpublished Master of Science Thesis, Department of Anthropology. The University of Tennessee, Knoxville, Tennessee, USA.

Miller, M.L., Freeland, R.S., Koppenjan, S.K., 2002. Searching for concealed human remains using GPR imaging of decomposition. Ninth International Conference on Groundpenetrating Radar. Proceedings of SPIE. 4758 (2002) 539-544. 
DISTRIBUTION LIST

U.S. Department of Energy

1 copy

National Nuclear Security Administration

Nevada Site Office

Technical Library

P.O. Box 98518

Las Vegas, NV 89193-8518

U.S. Department of Energy

1 copy

National Nuclear Security Administration

Nevada Site Office

Public Reading Facility

P.O. Box 98518

Las Vegas, NV 89193-8518

U.S. Department of Energy

1 electronic copy

Office of Scientific and Technical Information

P.O. Box 62

Oak Ridge, TN 37831-0062 